\title{
Effects of malathion exposure on glucose tolerance test in diabetic rats; emphasis on oxidative stress and blood concentration of malathion by gas chromatography mass spectrometry
}

\author{
Seyedeh-Azam Hosseini ${ }^{a}$, Ali Faghihi zarandi ${ }^{\mathrm{b}}$ and Somayyeh Karami-Mohajeri, ${ }^{\mathrm{a}, \mathrm{c}, *}$ \\ a Pharmaceutics Research Center, Institute of Neuropharmacology, Kerman University of Medical Sciences, Kerman, Iran. \\ ${ }^{b}$ Department of Occupational Health Engineering, School of Public Health, , Kerman University of Medical Sciences, Kerman, Iran. \\ ' Department of Toxicology and Pharmacology, School of Pharmacy, Kerman University of Medical Sciences, Kerman, Iran
}

\section{A R T I C L E I N F O :}

Received 25 Feb 2021

Revised form 29 Apr 2021

Accepted 21 May 2021

Available online 29 Jun 2021

\section{Keywords:}

Malathion,

Blood samples,

Diabetes,

Oxidative stress,

Erythrocyte,

Magnetic graphene oxide,

Gas chromatography mass spectrometry

\begin{abstract}
A B S T R A C T
Malathion is one of the widely used broad-spectrum organophosphate insecticides (OPI) in Iran. Malathion affects carbohydrate metabolism, causes hyperglycemia and increases the risk of diabetes. The present study was undertaken to investigate the potential of malathion to exacerbate diabetes-induced oxidative stress and impairment in blood glucose level and glucose tolerance in a sub-acute study. Malathion concentration in blood was analyzed with gas chromatography mass spectrometry (GC-MS) after sample preparation of blood samples based on magnetic $\mathrm{Fe}_{3} \mathrm{O}_{4}$-supported graphene oxide $\left(\mathrm{Fe}_{3} \mathrm{O}_{4} @ \mathrm{GO}\right)$ nanoparticles. Type 1 diabetes was experimentally induced by intraperitoneal administration of streptozocin $\left(65 \mathrm{mg} \mathrm{kg}^{-1}\right)$. Diabetic and non-diabetic rats were treated with malathion at the dose of 150 $\mathrm{mg} \mathrm{kg}^{-1} \mathrm{day}^{-1}$ or $0.5-4.0 \mathrm{mg} \mathrm{L}^{-1}$ in blood for 4 weeks. Fasting blood glucose was measured every week. At the end of the study, blood samples were investigated for markers of oxidative stress. Exposure to multiple doses of malathion decreased the total antioxidant capacity of plasma and the activity of catalase and superoxide dismutase enzymes in diabetic rats. Blood glucose and glucose tolerance test (GTT) and oxidative damages did not change significantly in diabetic rats exposed to malathion. However, malathion concentration in blood caused to increase GTT in malathion-treated non-diabetic rats. Taking together, our findings provide evidence that daily exposure to malathion for 4 weeks tends to exacerbate the decrease in blood antioxidant status and protein carbonylation in diabetic rats.
\end{abstract}

\section{Introduction}

The agricultural application of pesticides in the world has been linked to a wide range of human health hazards through occupational, accidental, and intentional exposures [1]. It seems that among

\footnotetext{
*Corresponding Author: Somayyeh Karami-Mohajeri

Email: s_karami@kmu.ac.ir, somayyehkarami@gmail.com https://doi.org/10.24200/amecj.v4.i02.141
}

all pesticides, organophosphate insecticides (OPI) are more toxic to vertebrates with low mammalian toxicity [2, 3]. OPI inhibit acetylcholinesterase (AChE), which leads to the accumulation of acetylcholine in the cholinergic synapses and interfere with the normal function of the nervous system [4]. However, it has been shown that these pesticides have different toxicities in vivo and in vitro through AChE-independent mechanisms $[5,6]$. 
OPI influences normal glucose homeostasis and carbohydrate metabolism and induces oxidative and nitrosative stress [7, 8]. Many techniques such as, UV-VIS, gas chromatography mass spectrometry, High Performance Liquid Chromatography (HPLC) and Liquid Chromatography [9, 10] were used for OPI and pesticides determination. The blood had difficulty matrixes and so must be treatment. Many sample preparation were used for treatment of blood samples for determination seven pesticides (malathion, methyl isofenphos, dichlorvos, chlorpyrifos, phenthoste, $p, p^{\prime}$-DDD, $p, p^{\prime}$-DDE) in blood samples based on a quick, easy, cheap, effective, rugged and safe (QuEChERS) sample preparation method. Occasionally, the $\mathrm{Fe}_{3} \mathrm{O}_{4}$ magnetic nanoparticles (MNPs) as the new adsorbing material was used for treatment of blood samples [11-14]. Although the foremost mechanism for hyperglycemia induced by OPI has not been recognized yet, some explanations are mentioned such as physiological stress, oxidative stress, paraoxonase enzyme inhibition, nitrosative stress, pancreatitis, cholinesterase inhibition, adrenal gland stimulation, and disturbance in liver tryptophan metabolism [15]. The human body is constantly exposed to various factors that contribute to the production of reactive oxygen species called free radicals. Imbalance between free radicals production and antioxidant systems lead to oxidative stress, which contributed to occurrence of the pathological conditions such as diabetes and development of diabetic complications [16-19]. Many toxic chemicals can generate reactive oxygen and trigger diabetes and hyperglycemia by induction of apoptosis in beta cells $[20,21]$. Some evidence points to the longterm effects of OPI on glucose metabolism and increased risk of diabetes [15]. Malathion, one the of most popular OPI, has been used widely in agriculture, industry, and also for therapeutic purposes in humans (anti-louse) and animals (antiectoparasites) [22]. Malathion alters the pathways of carbohydrate metabolism mainly though increase in the activity of glycogen phosphorylase, phosphofructokinase, phosphoenolpyruvate carboxykinase, and hexokinase which affects glycolysis, gluconeogenesis, and glycogenolysis $[15,23]$. Induction of oxidative and nitrosative stress in hepatocytes and pancreas beta cells are other contributing factors in hyperglycemia caused by Malathion [7, 23]. Activation of redox sensitive kinases and induction of oxidative stress in muscle cells after exposure to sub-toxic dose of malathion impairs insulin signaling and muscle glucose uptake and consequently causes insulin resistance state [24]. Hence, the present work has been designed to determine whether sub-acute exposure to repeated non-lethal dose of malathion can impair blood glucose control and exacerbate oxidative stress in diabetic rats. To do so, fasting blood glucose (FBG), glucose tolerance test (GTT), and biomarkers of oxidative damage were measured in non-diabetic and diabetic rats treated orally by sublethal dose of malathion for 4 weeks.

\section{Materials and methods}

\subsection{Chemicals and methods}

Technical-grade malathion, which contains $>96 \%$ malathion, was obtained from the ShimiKeshavarz PesticidesProduction Company(Tehran, Iran). The name of malathion based on IUPAC (International Union of Pure andApplied Chemistry) is diethyl(dimethoxythiophosphorylthio) succinate; S-1,2-bis(ethoxycarbonyl) ethyl-O,O-dimethyl phosphorodithioate (CAS N.: 121-75-5, Sigma, Germany) and UV spectrum of malathion in acetonitrile (CAS N.: 75-05-08, Merck, ACN) was shown in Schema 1. All other materials were purchased from the Merck and Sigma-Aldrich Chemical Company (St. Louis, MO). The $\mathrm{HNO}_{3}$, $\mathrm{HCl}$, polyoxyethylene octyl phenyl ether (MTX100, CAS N: 9002-93-1, Sigma, Germany), acetone and toluene (CAS N: 108-88-3, Merck) were purchased from Merck, Germany. Anhydrous magnesium sulfate (CAS N: 10034-99-8), sodium chloride was purchased from Sigma (Germany). Acetonitrile $(\mathrm{ACN})$ and methanol were purchased from Sigma Company (Germany). GC-MS (Agilent 7890A/5975C, USA) with HP-5MS column (30 m $\times 0.25 \mathrm{~mm}$ i.d.,) with flow of $1 \mathrm{~mL}$ per minute of 


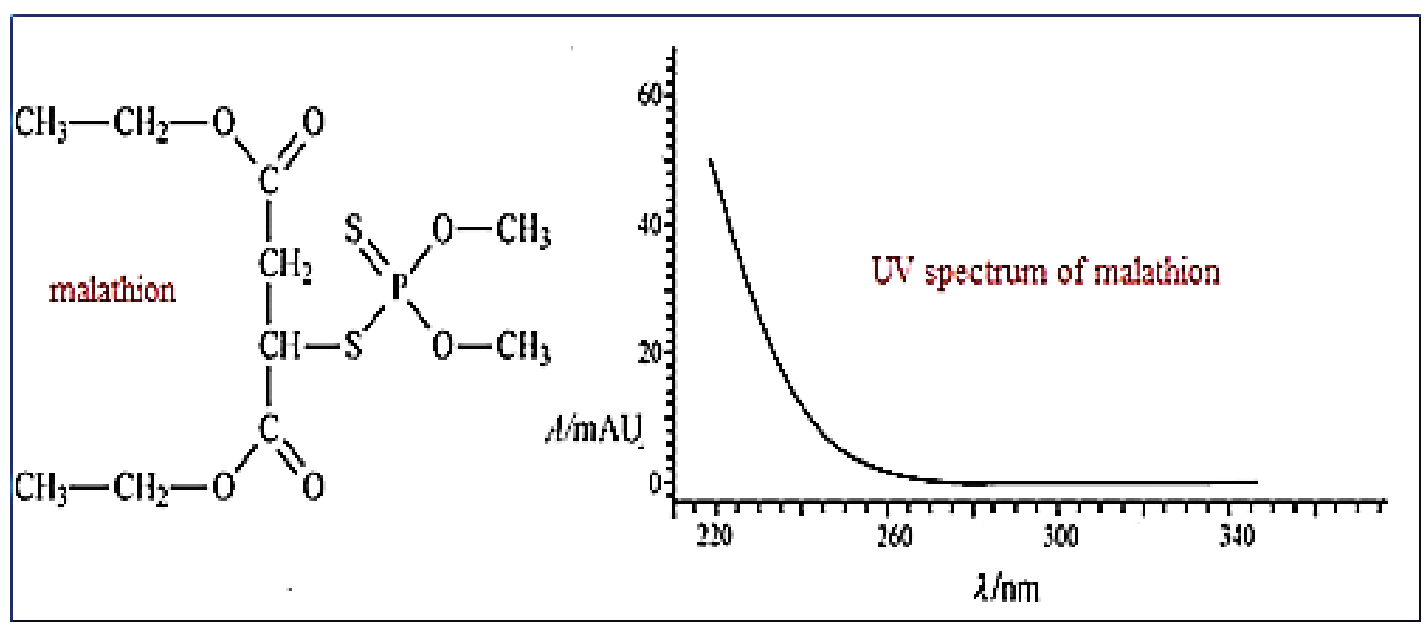

Shema 1. The structure and UV spectrum of malathion

He was used for qualitatively and quantitatively detecting pesticides in blood. Because blood is a complex matrix, and pesticides in blood are usually at low concentrations, the separation of malathion and elimination of interference in blood have needed a special sample treatment. Working standard solutions were prepared in DW. All these solutions were stored at $4{ }^{\circ} \mathrm{C}$ without any light. The range of this study of malathion in blood is $0.3-4.4$ $\mu \mathrm{g} \mathrm{mL} \mathrm{mL}^{-1}$ by GC-MS after dilution $1 \mathrm{~mL}$ of blood with DW.

\subsection{Synthesis of magnetic $\mathrm{Fe}_{3} \mathrm{O}_{4}$-supported graphene oxide}

The magnetic $\mathrm{Fe}_{3} \mathrm{O}_{4}$-supported graphene oxide
(MNGO, $\mathrm{Fe}_{3} \mathrm{O}_{4} @ \mathrm{NGO}$ ) were prepared by coprecipitation of $\mathrm{FeCl}_{2} \cdot 4 \mathrm{H}_{2} \mathrm{O}$ and $\mathrm{FeCl}_{3} \cdot 6 \mathrm{H}_{2} \mathrm{O}$, in the presence of NGO [19]. firstly, a liquid solution of $\mathrm{FeCl}_{2} \cdot 4 \mathrm{H}_{2} \mathrm{O} / \mathrm{FeCl}_{3} \cdot 6 \mathrm{H}_{2} \mathrm{O}$ was prepared (molar ratio $=1: 2$ ). The weight ratio of $\mathrm{FeCl}_{3} / \mathrm{NGO}$ in the product was $\mathrm{mFeCl}_{3}: \mathrm{mGO}=20: 1$. To prepare the magnetic graphene oxide $\left(\mathrm{Fe}_{3} \mathrm{O}_{4} @ \mathrm{NGO}\right)$, $10 \mathrm{mg}$ of graphene oxide mixed with $10 \mathrm{~mL}$ of DW and ultrasonicated for $30 \mathrm{~min} \mathrm{[19].} \mathrm{Then,}$ $12.5 \mathrm{~mL}$ solution of $\mathrm{FeCl}_{2} \cdot 4 \mathrm{H}_{2} \mathrm{O}(125 \mathrm{mg})$ and $\mathrm{FeCl}_{3} \cdot 6 \mathrm{H}_{2} \mathrm{O}(200 \mathrm{mg})$ in DW was added to the mixture. Finally, the $\mathrm{pH}$ of 11 was achieved by $30 \%$ ammonia solution and the temperature was adjusted to $70{ }^{\circ} \mathrm{C}$ (Fig. 1).

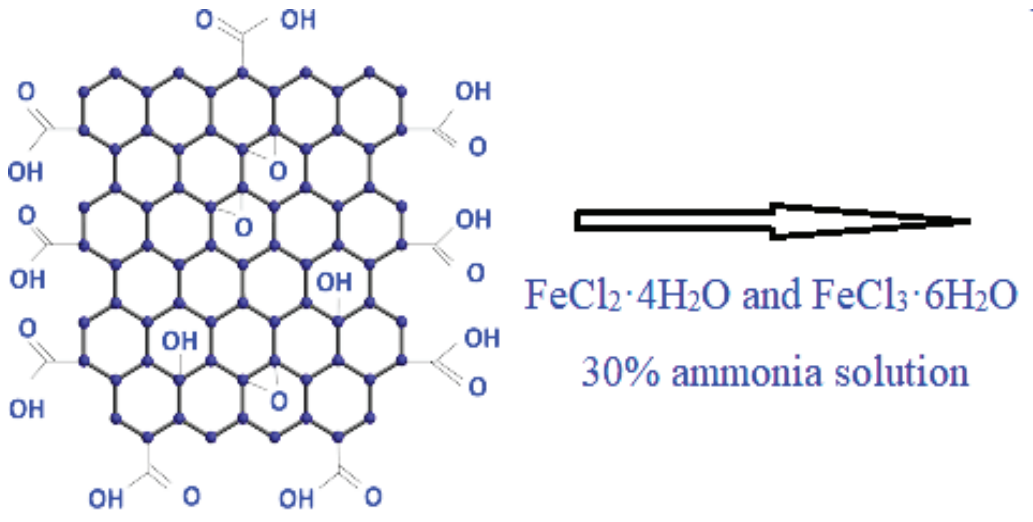

NGO

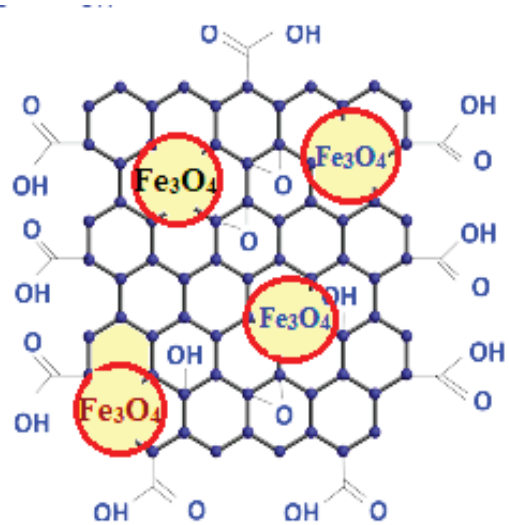

$\mathrm{Fe}_{3} \mathrm{O}_{4} @ \mathrm{NGO}$

Fig.1. Synthesis of magnetic $\mathrm{Fe}_{3} \mathrm{O}_{4}$-supported graphene oxide [19] 


\subsection{Sample Extraction Procedure for malathion in blood}

The sample preparation of blood samples in rat were prepared based on quick, easy, cheap, effective, rugged and safe (QuECh- ERS) method based on $\mathrm{Fe}_{3} \mathrm{O}_{4}$ magnetic nanoparticles (MNPs) functionalized with NGO. The free of DDC, DDT and malathion pesticide in blood samples were used as blank solution. $1 \mathrm{~mL}$ of rat blood sample was added into $10 \mathrm{~mL}$ of vial. Standard volumes of DDC, DDT and malathion pesticide were added to the vial, and then shaken for $1 \mathrm{~min}$. The samples were extracted with $2 \mathrm{~mL}$ acetonitrile for $30 \mathrm{~s}$. Anhydrous $\mathrm{NaCl}(0.1 \mathrm{~g}) / \mathrm{MgSO}_{4}(0.3 \mathrm{~g})$ were added to the mixture centrifuging at $4000 \mathrm{rpm}$ for $5 \mathrm{~min}$ and then, the supernatant moved to $10 \mathrm{~mL}$ of vial include $\mathrm{Fe}_{3} \mathrm{O}_{4} @ \mathrm{NGO}(0.04 \mathrm{~g})$. The vial shake for 1 min, and the supernatant separated with an external magnet. Finally, the sample was dissolved in $50 \mu \mathrm{L}$ of acetonitrile and $1 \mu \mathrm{L}$ of solution was determined by GC-MS. The detection limits (LOD)and linear range(LR) of the QuECh- ERS method based on $\mathrm{Fe}_{3} \mathrm{O}_{4} @$ NGO obtained $0.1 \mu \mathrm{g} \mathrm{mL} \mathrm{mL}^{-1}$ and $0.3-4.4 \mu \mathrm{g}$ $\mathrm{mL}^{-1}$ with recoveries more than $95 \%$ [9-12].

\subsection{Animals}

Male Wistar rats weighing $211.5 \pm 10.6$ grams were fed with standard diet and kept under 12:12 hour light:dark cycle, at the temperature of $20^{\circ} \mathrm{C}$ and relative humidity of 25 to $30 \%$. This study received ethical approval (Code: IR.79.KMU.REC.139579) from the local ethical committee of the Kerman University of Medical Sciences.

\subsection{Pilot experiment}

A pilot test is designed to determine an oral dose of malathion which inhibits $30 \%$ of plasma ChE activity without significant physiological consequences and mortality within 4 weeks [25]. The treated groups (Ten rats in each group) received the oral doses of $75,100,150$, and $300 \mathrm{mg} / \mathrm{kg} /$ day of malathion dissolved in corn oil for 4 weeks, while the controls received only corn oil. Blood samples were taken at the end of each week for measurement of plasma ChE activity according to the Ellman's colorimetric method with slight modification [26]. Briefly, $300 \mu 1$ of 5,5'-Dithiobis(2-nitrobenzoic acid) (0.25 $\mathrm{mM}$ in $0.1 \mathrm{M}$ phosphate buffer, $\mathrm{pH} 7.4)$ was added to $10 \mu \mathrm{l}$ of plasma and after 5 minutes $10 \mu \mathrm{l}$ of acetylthiocholine iodide $(3 \mathrm{mM})$ was added and the absorbance was measured at $412 \mathrm{~nm}$ for 5 minutes. The activity of $\mathrm{ChE}$ was calculated according to the molar extinction coefficient of 5-thio-2-nitrobenzoate $\left(13.6 \times 10^{3} \mathrm{M}^{-1} \mathrm{~cm}^{-1}\right)$ and expressed as $\mathrm{nMol} \mathrm{min}^{-1} \mathrm{~mL}^{-1}$. As depicted in Table 1, malathion at the dose of $150 \mathrm{mg} \mathrm{kg}^{-1} \mathrm{day}^{-1}$ during 4 weeks inhibited $30 \%$ of the plasma ChE activity (663.40 \pm 72.09$)$ compared with the control group $(1029.67 \pm 84.52)$ with no mortality or acute toxic effects in rats.

Table 1. Plasma cholinesterase activity as percent of inhibition (\%) after 4 weeks of daily administration of oral multiple doses of malathion.

\begin{tabular}{|c|c|c|c|c|c|}
\hline \multirow{2}{*}{ Week } & \multicolumn{5}{|c|}{ Malathion (mg kg-1 day $^{-1}$ ) } \\
\hline & $\mathbf{0}$ & 75 & 100 & 150 & 200 \\
\hline $1 \mathrm{st}$ & $99.4 \pm 4.3$ & $93.2 \pm 1.8$ & $86.6 \pm 2.1 * * *$ & $76.4 \pm 5.7 * * *$ & $63.8 \pm 3.3 * * *$ \\
\hline 2 nd & $101.4 \pm 9.1$ & $93.3 \pm 1.4^{*}$ & $86.4 \pm 2.2 * * *$ & $77.3 \pm 5.5^{* * *}$ & $63.0 \pm 2.6^{* * *}$ \\
\hline $3 \mathrm{rd}$ & $99.5 \pm 5.8$ & $91.4 \pm 1.8^{*}$ & $85.2 \pm 3.2 * * *$ & $71.0 \pm 4.2^{* * *}$ & $59.1 \pm 6.6^{* * *}$ \\
\hline 4 th & $100.6 \pm 7.5$ & $84.5 \pm 1.6^{* * *}$ & $80.8 \pm 1.9 * * *$ & $66.7 \pm 2.9^{* * *}$ & $54.9 \pm 4.8^{* * *}$ \\
\hline
\end{tabular}

Data was expressed as mean $\pm \mathrm{SD} ; \mathrm{n}=10 ; * P<0.05$ and $* * * P<0.001$, significantly different from the control values (One-way ANOVA followed by multiple comparison test). 


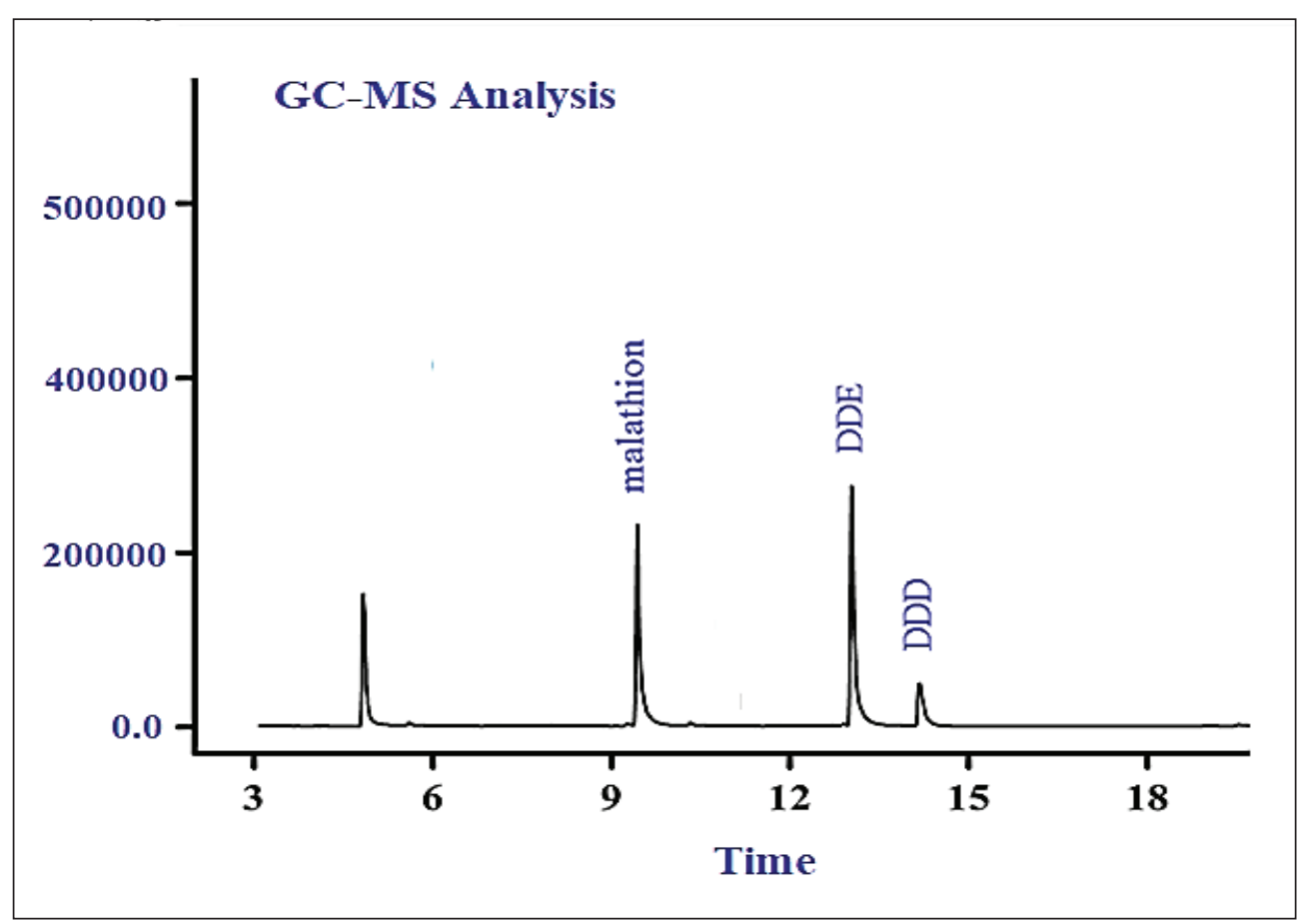

Fig.2. The Chromatographic of DDC, DDT and malathion pesticides by GC-MS

\subsection{Measurement of malathion}

GC-MS (Agilent 7890A/5975C, USA) with HP$5 \mathrm{MS}$ column $(30 \mathrm{~m} \times 0.25 \mathrm{~mm}$ i.d., $)$ with flow of $1 \mathrm{~mL}$ per minute of He was used for DDC, DDT and malathion pesticide in blood rats. The splitless injector was used. By GC-MS, the main parameters such as, the inlet and interface temperature set at 250 and $280{ }^{\circ} \mathrm{C}$, respectively. The source of MS tuned $220^{\circ} \mathrm{C}$ and ionization energy was less than $65-\mathrm{eV}$. The oven temperature was first at $100{ }^{\circ} \mathrm{C}$ (1.5 min), and increased up to $200-280{ }^{\circ} \mathrm{C}(20-6$ ${ }^{\circ} \mathrm{C} / \mathrm{min}$ ). The Chromatographic of DDC, DDT and malathion pesticides was shown in Figure 2 [9-13].

\subsection{Induction of diabetes in rats}

Type 1 diabetes was induced by intraperitoneal injection of a single dose streptozotocin (STZ) solubilized in $0.1 \mathrm{M}$ trisodium citrate buffer $(\mathrm{pH}$, 4.5) at the dose of $65 \mathrm{mg} \mathrm{kg}^{-1}$, according to the method described by Furman [27]. STZ-treated rats received $10 \%$ of sucrose instead of water for $48 \mathrm{~h}$. Induction of diabetes was verified by measurement of FBG four times (1, 3 and 28 days after the beginning of treatment) to ensure that the hyperglycemia $\left(\mathrm{FBG} \geq 250 \mathrm{mg} \mathrm{dL}^{-1}\right)$ was established.
Polyuria and polydipsia were also monitored by observation of the amount of consumed water and the frequency of bedding exchange.

\subsection{Experimental design, animal treatment, and sample collection}

Forty rats were randomly allocated to four groups of ten as follows:

Control: Healthy rats that only received corn oil orally.

DM: Diabetic rats received corn oil orally.

MT: Healthy rats received malathion $\left(150 \mathrm{mg} \mathrm{kg}^{-1}\right.$ day $^{-1}$, oral) for 4 weeks.

DM+MT: Diabetic rats received malathion (150 $\mathrm{mg} \mathrm{kg}^{-1}$ day $^{-1}$, oral) for 4 weeks.

At the end of the experiment, all rats were anesthetized by ketamine $(60 \mathrm{mg} / \mathrm{kg})$ and xylazin $(6$ $\left.\mathrm{mg} \mathrm{kg}^{-1}\right)$ and after collection of blood sample through cardiac puncture sacrificed by cervical dislocation. Blood samples immediately centrifuged at $3000 \mathrm{~g}$ for 15 minutes for separation of plasma. To prepare hemolysate, $250 \mu \mathrm{l}$ of distilled water was added to $50 \mu 1$ of packed RBCs and mixed thoroughly. Plasma samples and hemolysate were kept at -80 ${ }^{\circ} \mathrm{C}$ for further experiments. 


\subsection{Measurement of FBG and GTT}

Blood glucose was measured in the blood sample obtained by a small cut on the tip of rat's tail immediately after overnight fasting using the commercial glucose diagnostic kit of Pars Azmoon Company (Tehran, Iran). For measurement of GTT, blood glucose was recorded every $30 \mathrm{~min}$ after oral administration of glucose $(2 \% \mathrm{w} / \mathrm{v})$. Area under the curve (AUC 0-120 min) of glucose concentration from 0 to 120 minutes after administration of glucose was calculated by the trapezoidal method [28].

\subsection{Measurement of oxidative stress}

\section{biomarkers by spectrophotometry}

\subsubsection{Measurement of total antioxidant}

\section{capacity of plasma}

Antioxidant capacity was measured by ferric reducing antioxidant power (FRAP) method. During the reaction in acidic $\mathrm{pH}$, the colorless ferric-tripyridyl triazine ( $\left.\mathrm{Fe}^{3+}-\mathrm{TPTZ}\right)$ is reduced to blue ferrous-tripyridyl triazine ( $\mathrm{Fe}^{2+}$-TPTZ) [29]. To perform this experiment, $10 \mu 1$ of plasma was added to $300 \mu$ FRAP reagent (1:1:10 mixture of $\mathrm{FeCl} 3,10 \mathrm{mM}$ TPTZ, and $0.3 \mathrm{M}$ acetate buffer at $\mathrm{pH}$ 3.6). After incubation at $37^{\circ} \mathrm{C}$ for 10 minutes, the absorbance was read at $593 \mathrm{~nm}$. Finally, FRAP was expressed as $\mathrm{mmol} \mathrm{Fe}^{2+} / \mathrm{mg}$ protein according to the standard curve of $\mathrm{FeSO}_{4}$.

\subsubsection{Measurement of glutathione (GSH) content}

According to the Elman method, thiol groups react by 5,5'-dithio-bis(2-nitrobenzoic acid) (DTNB) and produce yellow complex [30]. Briefly, $250 \mu \mathrm{L}$ of TCA $10 \%$ were added to $500 \mu \mathrm{L}$ of hemolysate and centrifuged at $3500 \mathrm{~g}$ for 35 minutes. Then, $200 \mu \mathrm{L}$ of Tris buffer and $500 \mu \mathrm{L}$ DTNB $(10 \mathrm{mM}$ in $0.1 \mathrm{M}$ phosphate buffer, $\mathrm{pH} 8$ ) were added to the supernatant and incubated in the dark at room temperature for 15 minutes. The absorbance was read at $412 \mathrm{~nm}$ and total thiol was expressed as $\mathrm{nmol} / \mathrm{mg}$ protein according to the standard curve of GSH.

\subsubsection{Measurement of superoxide dismutase (SOD) activity}

SOD activity was measured based on autoxidation rate of pyrogallol at $420 \mathrm{~nm}$ by the Worthington method with minor modification [31]. Briefly, the absorbance of pyrogallol ( $2 \mathrm{mM}$ pyrogallol in Tris$\mathrm{HCl}$ buffer, $\mathrm{pH}$ 8.2) was determined kinetically alone and after the addition of $50 \mu \mathrm{l}$ of hemolysate. The amount of SOD needed for 50\% inhibition of the pyrogallol autoxidation was considered as one unit of SOD activity and expressed as U/mg protein.

\subsubsection{Measurement of catalase (CAT) activity}

According to Cohen method [32], $1 \mathrm{ml}$ of $30 \mathrm{mM}$ $\mathrm{H}_{2} \mathrm{O}_{2}$ and $50 \mu \mathrm{l}$ of the hemolysate was added to 2 $\mathrm{ml}$ of phosphate buffer $(50 \mathrm{mM}, \mathrm{pH} 7.0)$ and then the absorbance was measured kinetically at 240 $\mathrm{nm}$. One unit of catalase activity is equal to $1 \mu \mathrm{M}$ $\mathrm{H}_{2} \mathrm{O}_{2}$ decomposed per minute. The concentration of $\mathrm{H}_{2} \mathrm{O}_{2}$ was calculated using the following equation: $\mathrm{H}_{2} \mathrm{O}_{2}(\mu \mathrm{M})=($ Absorbance at $240 \mathrm{~nm} \times 1000) / 43.6$ $\left.\mathrm{M}^{-1} \mathrm{~cm}^{-1}\right)$. Catalase activity was expressed as $\mathrm{U} / \mathrm{mg}$ protein.

\subsubsection{Measurement of lipid peroxidation}

Malondialdehyde (MDA) as the end-product of lipid peroxidation was measured based on the absorbance of MDA-thiobarbituric acid (TBA) complex in acidic and high-temperature condition [33]. Briefly, $100 \mu \mathrm{l}$ of hemolysate was deproteinized by TCA $10 \%$ and centrifuged at 3500 $\mathrm{g}$ for 35 minutes. One $\mathrm{ml}$ of sulfuric acid $0.05 \%$ and $800 \mu \mathrm{l}$ of TBA $(0.2 \%)$ were then added to the precipitant and boiled at $95{ }^{\circ} \mathrm{C}$ for 30 minutes. Then, MDA-TBA complex was extracted by $800 \mu \mathrm{l}$ n-butanol and the absorbance was read at $532 \mathrm{~nm}$. The level of MDA was expressed as nmol MDA/ mg protein according to the MDA standard curve.

\subsubsection{Measurement of protein carbonylation}

Protein carbonylation was measured according to Levin et al. method [34]. Throughout the method, $100 \mu 1$ of hemolysate was added to $500 \mu 1$ of TCA $20 \%$, kept at room temperature for 10 minutes, and 
Table 2. Fasting blood glucose (FBG), Glucose tolerance test (GGT) and weight of rats on day 1, 3, and 28 in non-diabetic rats received corn oil (Control) and malathion (MT) and in diabetic rats received corn oil (DM) and malathion (DM + MT).

\begin{tabular}{|c|c|c|c|c|}
\hline Time & & Day 1 & Day 3 & Day 28 \\
\hline \multirow{4}{*}{ FBG (mg/dl) } & Control & $62.0 \pm 9.7$ & $74.3 \pm 25.5$ & $74.0 \pm 14.7$ \\
\hline & $\mathrm{DM}$ & $108.4 \pm 18.6$ & $424.8 \pm 28.9 * * *$ & $395.4 \pm 18.1 * * *$ \\
\hline & MT & $108.6 \pm 19.3$ & $89.1 \pm 15.0$ & $90.4 \pm 21.0$ \\
\hline & $\mathrm{DM}+\mathrm{MT}$ & $133.25 \pm 9.1$ & $383.2 \pm 19.1 * * *$ & $413.7 \pm 12.1 * * *$ \\
\hline \multirow{4}{*}{$\begin{array}{l}\text { GTT (AUC } \\
0-120 \mathrm{~min})\end{array}$} & Control & $9325 \pm 409$ & $\mathrm{NC}$ & $11990 \pm 658.2$ \\
\hline & $\mathrm{DM}$ & $11975 \pm 521$ & $\mathrm{NC}$ & $47574 \pm 3758^{* * *}$ \\
\hline & MT & $10010.5 \pm 688$ & $\mathrm{NC}$ & $17886 \pm 1438 *$ \\
\hline & $\mathrm{DM}+\mathrm{MT}$ & $10834 \pm 674$ & $\mathrm{NC}$ & $50577 \pm 1256^{* * *}$ \\
\hline \multirow{4}{*}{ Weight (gr) } & Control & $211.5 \pm 10.6$ & $213.3 \pm 9.2$ & $263.7 \pm 12.33$ \\
\hline & $\mathrm{DM}$ & $189.4 \pm 8.5$ & $182.4 \pm 12.3$ & $158.4 \pm 8.2^{* *}$ \\
\hline & MT & $198.4 \pm 8.3$ & $198.8 \pm 7.7$ & $214.6 \pm 7.1$ \\
\hline & $\mathrm{DM}+\mathrm{MT}$ & $212.6 \pm 2.6$ & $214.9 \pm 3.1$ & $162.7 \pm 7.9^{* * *}$ \\
\hline
\end{tabular}

Data was expressed as mean $\pm \mathrm{SD} ; \mathrm{n}=10 ; * p<0.05, * * p<0.01$, and $* * * p<0.001$, significantly different from the control values (One-way ANOVA followed by multiple comparison test). NC: not calculated.

centrifuged. The supernatant was discarded and $1 \mathrm{ml}$ 4-dinitrophenylhydrazine (DNPH, $10 \mathrm{mM}$ ) was added to the pellet and incubated at $37{ }^{\circ} \mathrm{C}$ for 50 minutes. Then, $1 \mathrm{ml}$ of TCA $20 \%$ was added and centrifuged. The remaining pellet was washed with $1 \mathrm{~mL}$ of ethanol and ethyl acetate solution (1:1 ratio). Then, $1 \mathrm{~mL}$ of guanidine hydrochloride $6 \mathrm{M}$ was added and incubated at $37^{\circ} \mathrm{C}$ for 30 minutes. After centrifugation, the supernatant was transferred to a 96-well plate and the absorbance was measured at $380 \mathrm{~nm}$. The carbonyl content was calculated using the molar extinction coefficient of $22,000 \mathrm{M}^{-1} \mathrm{~cm}^{-1}$ and expressed as $\mathrm{nmol} / \mathrm{mg}$ protein

\subsection{Measurement of protein concentration}

Protein concentration in the samples was measured according to the Bradford's method [35]. Briefly, $200 \mu \mathrm{l}$ of Bradford reagent (100 mg coomassie brilliant blue G-250 was dissolved in $50 \mathrm{ml} 95 \%$ ethanol and then $100 \mathrm{ml} \mathrm{85 \%}$ phosphoric acid and $850 \mathrm{ml}$ of distilled water was added) were mixed with $50 \mu$ of samples and bovina serum albumin (BSA) as standard in 96-well plate. After five minutes' incubation at $37{ }^{\circ} \mathrm{C}$, the absorbance was measured at $595 \mathrm{~nm}$ and the protein concentration was expressed as $\mathrm{mg} \mathrm{mL}^{-1}$ of samples according to the standard curve of BSA.

\subsection{Statistical analysis}

Data were analyzed by using commercially available SPSS software. Data was analyzed by one-way ANOVA followed by Tukey's multiple comparison test. Results were presented as mean $\pm \mathrm{SD}$ (Standard Deviation) and $p$ values less than 0.05 were regarded as statistically significant.

\section{Results and discussion}

\subsection{Malathion blood concentration}

The blood malathion firstly determined by GC-MS analysis after oral intake in rats. The blood analysis of malathion indicates that oral administration of malathion at the dose of $50-150 \mathrm{mg} \mathrm{kg}^{-1}$ day $^{-1}$ caused a blood concentration of malathion in the range of $0.5-4.0 \mu \mathrm{g} \mathrm{mL}^{-1}$.

\subsection{Induction of diabetes in rats}

As shown in Table 2, administration of STZ at the single dose of $65 \mathrm{mg} \mathrm{kg}^{-1}$ caused significant hyperglycemia $\left(\mathrm{FBG}=424.8 \pm 28.9 \mathrm{mg} \mathrm{dL}^{-1}, p\right.$ $<0.001$ ) and loss of body weight was compared with control group $\left(\mathrm{FBG}=74.3 \pm 25.5 \mathrm{mg} \mathrm{dL}^{-1}\right)$. Polyuria and polydipsia were other findings were observed in the diabetic rats within 4 weeks. 


\subsection{Effects on blood glucose}

As shown in Table 2, malathion at the dose of 150 $\mathrm{mg} \mathrm{kg}^{-1}$ did not result in a significant increase in FBG in diabetic rats compared with non-treated diabetic rats $(p=0.77)$ and in non-diabetic rats compared with control group $(p=0.72)$. On the other hand, malathion caused significant $(p=0.04)$ increase in AUC 0-120 of glucose concentration curve in non-diabetic rats. most previous studies showed that hyperglycemia in both short-term and longterm exposure to OPI happened due to disruption in glycolysis, glycogenolysis, and gluconeogenesis pathways [7] and impairment in insulin signaling and insulin-stimulated glucose uptake in muscle cells [24]. Also, a meta-analysis conducted by RamirezVargas et al. (2018), revealed that blood glucose concentrations were 3.3-fold higher in malathionexposed rats than in the control group [23]. In contrast, it should be noted that some studies show gradual increase in blood glucose and even hypoglycemia after malathion exposure [36-38]. It has been also reported that blood glucose in malathion-treated rats increased (2.2-fold) after $2 \mathrm{~h}$ but gradually decreased within $4 \mathrm{~h}$ [39]. It can be concluded that duration of exposure, dose, experimental protocols, time of blood sampling, and the mode of administration are variables which affects the toxicity of malathion. As the toxicity of malathion on carbohydrates, fats, and protein metabolism pathways is approved previously, significant effects on FBG and GTT might be obtained with increase in the number of examined animal and duration of exposure to malathion.

\subsection{Effects on antioxidants level}

The total antioxidant capacity of plasma in diabetic and non-diabetic rats exposed to malathion decreased significantly $(p<0.001)$ comparing to control group. Moreover, a considerable difference $(\mathrm{p}=0.009)$ was detected in malathion-treated diabetic rats compared to diabetic rats received corn oil (Fig. 3a). GSH level in RBCs decreased significantly $(p<0.001)$ in all groups compared to control group. However, there was no considerable difference $(\mathrm{p}=0.13)$ between diabetic and nondiabetic rats received malathion (Fig. 3b). The activity of SOD in RBCs decreased significantly in diabetic groups $(\mathrm{p}<0.05)$, and in diabetic and non-diabetic group received malathion ( $p$ $<0.001)$ compared to control group. Malathion decreased significantly $(p=0.0008)$ the activity of SOD in diabetic rats compared to diabetic group received corn oil (Fig. 3c). The activity of CAT in erythrocyte decreased significantly $(\mathrm{p}<$ 0.001) in all groups in comparison with control group. A significant $(\mathrm{p}=0.007)$ decrease was also observed in diabetic rats received malathion compared to diabetic groups (Fig. 3d). The results of this study indicated that both diabetes and subacute exposure to the sub-lethal dose of malathion reduced the activity of CAT and SOD enzymes and total antioxidant capacity of plasma and GSH level. Interestingly, malathion in diabetic rats intensified the reduction of total antioxidant capacity and the activity of antioxidant enzymes. These results are in agreement with previous studies, which have indicated that diabetic condition and exposure to OPI reduce the total antioxidant capacity of plasma $[7,40,41]$. Reduction in total thiol content which induces oxidative and nitrosative damages were also reported in OPI exposure [42-45].

\subsection{Effects on lipid peroxidation and protein carbonylation}

As shown in Table 3, lipid peroxidation and protein carbonylationindiabetic ratsas well as in diabetic and non-diabetic rats exposed to malathion significantly $(p<0.001)$ increased compared to control group. However, despite increase in the lipid peroxidation, no significant differences were observed between lipid peroxidation level in diabetic rats and diabetic rats exposed to malathion. Protein carbonylation was significantly $(p=0.042)$ increased in diabetic rats exposed to malathion compared to diabetic rats received corn oil. Generation of free radicals disables antioxidant systems and consequently exerts further destructive effects on cellular macromolecules [7, $15,40]$. Increase in protein carbonylation and lipid peroxidation revealed in the current study was in agreement with the findings of other studies [7, 46]. OPI increases lipid peroxidation and protein carbonylation in acute and sub-acute exposure 

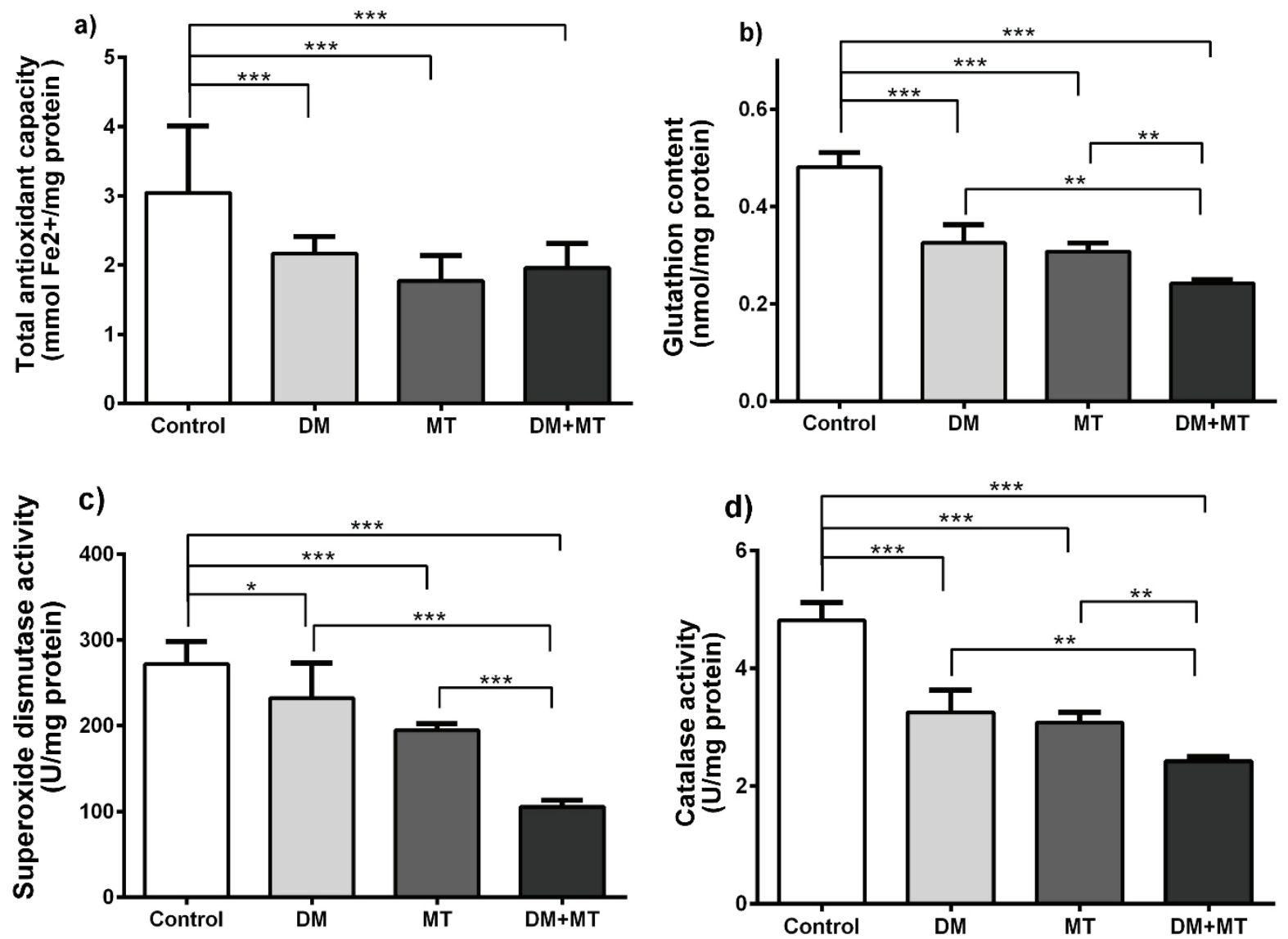

Fig. 3. Effects of malathion on antioxidants in the studied groups. a) Total antioxidant capacity of plasma, b) RBCs glutathione content, c) RBCs superoxide dismutase activity, d) RBCs catalase activity in healthy rats received corn oil (Control) and malathion (MT) and in diabetic rats received corn oil (DM) and malathion (DM $+\mathrm{MT}$ ) after 4 weeks. Data was expressed as mean $\pm \mathrm{SD} ; \mathrm{n}=10 ; * p<0.05, * * p<0.01$, and $* * * p<0.001$, significantly different between groups (One-way ANOVA followed by Tukey's multiple comparison test).

Table 3. Protein carbonylation and lipid peroxidation in non-diabetic rats received corn oil (Control) and malathion (MT) and in diabetic rats received corn oil (DM) and malathion (DM + MT) after 4 weeks.

\begin{tabular}{|c|c|c|c|c|c|}
\hline Parameters & Control & DM & & MT & $\mathbf{D M}+\mathbf{M T}$ \\
\hline Lipid peroxidation (nmol/mg protein) & $\begin{array}{l}0.64 \pm \\
0.13\end{array}$ & $\begin{array}{l}0 . \quad 86 \\
0.09 * * * \\
\end{array}$ & \pm & $\begin{array}{l}0.92 \\
0.10^{* * *}\end{array}$ & $0.99 \pm 0.15^{* * *}$ \\
\hline Carbonyl protein formation ( $\mathrm{nmol} / \mathrm{mg}$ protein) & $\begin{array}{l}0.92 \pm \\
0.15 \\
\end{array}$ & $\begin{array}{l}1.12 \\
0.13 * *\end{array}$ & \pm & $1.20 \pm 0.2^{* *}$ & $145 \pm 0.23 * * *$ \\
\hline
\end{tabular}

Data was expressed as mean $\pm \mathrm{SD} ; \mathrm{n}=10 ; * * p<0.01$ and $* * * p<0.001$, significantly different from the control values (One-way ANOVA followed by multiple comparison test).

[47-49]. Elevation in lipid peroxidation in diabetic rats exposed to monocrotophos, an OPI, was also reported by Vismaya and Rajini [44]. Increase in the MDA level indicates the susceptibility of cell membrane lipids against oxidative stress induced by malathion in diabetic rats.

\section{Conclusions}

Taking together, the results of this study imply that malathion aggravated decline in the enzymatic antioxidant defense system. Impairment in antioxidants capacity in long-term exposure to OPI causes further oxidative damages as a proposed 
mechanism for OPI-induced hyperglycemia. According to high prevalence of diabetes, it is recommended to conduct further in vivo, in vitro, and clinical studies to investigate effects of OPI on insulin release and blood glucose tolerance in diabetic subjects exposed to OPI. It is also recommended to evaluate effects of malathion on tissues contributing to or affected by hyperglycemia. Further consideration is also required to restrain the utilization of OPI, which are widely used in developing countries.

\section{Acknowledgement}

This manuscript was supported by Research Deputy of Kerman University of Medical Sciences.

\section{References}

[1] R.F. Clark, Insecticides: organic phosphorus compounds and carbamates. Goldfrank's Toxicological Emergencies. New York: McGraw-Hill Professional, 2002.

[2] M.D. Shah, M. Iqbal, Diazinon-induced oxidative stress and renal dysfunction in rats, Food Chem. Toxicol., 48 (2010) 3345-3353.

[3] M. Balali-Mood, H. Saber, Recent advances in the treatment of organophosphorous poisonings, Iran. J. Med. Sci., 37 (2012) 74-91.

[4] D.M. Roberts, C.K. Aaron, Management of acute organophosphorus pesticide poisoning, British Med. J., 334 (2007) 629-634.

[5] M. Abdollahi, S. Karami-Mohajeri, A comprehensive review on experimental and clinical findings in intermediate syndrome caused by organophosphate poisoning, Toxicol. Appl. Pharmacol., 258 (2012) 309-314.

[6] S. Karami-Mohajeri, S. Nikfar, M. Abdollahi, A systematic review on the nerve-muscle electrophysiology in human organophosphorus pesticide exposure, Hum. Exp. Toxicol., 33 (2014) 92-102.

[7] S. Karami-Mohajeri, M. Abdollahi, Toxic influence of organophosphate, carbamate, and organochlorine pesticides on cellular metabolism of lipids, proteins, and carbohydrates: a systematic review, Hum.
Exp. Toxicol., 30 (2011) 1119-1140.

[8] M. Abdollahi, Pesticides and oxidative stress: a review, Med, Sci, Monit., 10 (2004) RA141-7.

[9] N. Brandhonneur, A micro-QuEChERS method coupled to GC-MS for the quantification of pesticides in specific maternal and fetal tissues, J. Pharm. Biomed. Anal., 104 (2015) 90-96.

[10] G. Famiglini, et al., The rapid measurement of benzodiazepines in a milk-based alcoholic beverage using QuEChERS extraction and GC-MS analysis, J. Anal. Toxicol., 39 (2015) 306-312.

[11] E. Gallardo, Determination of quinalphos in blood and urine by direct solid-phase microextraction combined with gas chromatography-mass spectrometry, J. Chromatogr. B, Anal. Technol. Biomed. Life Sci., 832 (2006) 162-168.

[12] M. Liang, Fe3O4 magnetic nanoparticle peroxidase mimetic-based colorimetric assay for the rapid detection of organophosphorus pesticide and nerve agent, Anal. Chem., 85 (2013) 308-312.

[13] X. Deng, Rapid and effective sample cleanup based on magnetic multiwalled carbon nanotubes for the determination of pesticide residues in tea by gas chromatography-mass spectrometry, Food Chem., 145 (2014) 853858.

[14] M.K. Abbasabadi, H. Shirkhanloo, Speciation of cadmium in human blood samples based on $\mathrm{Fe}(3) \mathrm{O}(4)$-supported naphthalene-1-thiolfunctionalized graphene oxide nanocomposite by ultrasound-assisted dispersive magnetic micro solid phase extraction, J. Pharm. Biomed. Anal., 189 (2020) 113455.

[15] R. Rahimi, M. Abdollahi, A review on the mechanisms involved in hyperglycemia induced by organophosphorus pesticides, Pestic. Biochem. Physiol., 88 (2007) 115-121.

[16] U. Asmat, K. Abad, K. Ismail, Diabetes mellitus and oxidative stress-A concise review, Saudi Pharm. J., 24 (2016) 547-553.

[17] U. Karunakaran, K.G. Park, A systematic 
review of oxidative stress and safety of antioxidants in diabetes: focus on islets and their defense, Diabetes Metab. J., 37 (2013) 106-112.

[18] F. Giacco, M. Brownlee, Oxidative stress and diabetic complications, Circ. Res., 107 (2010) 1058-1070.

[19] S. Shahvali, A. Shahesmaeili, S. KaramiMohajeri, The correlation between blood oxidative stress and sialic acid content in diabetic patients with nephropathy, hypertension, and hyperlipidemia, Diabetol. Int., 2019 (2019) 1-8.

[20] R. Franco, Environmental toxicity, oxidative stress and apoptosis: menage a trois, Mutat. Res., 674 (2009) 3-22.

[21] K. Van Dyke, Oxidative/nitrosative stresses trigger type I diabetes: preventable in streptozotocin rats and detectable in human disease, Ann. N Y Acad. Sci., 1203 (2010) 138-145.

[22] N.S. Babu, Effects of subchronic malathion exposure on the pharmacokinetic disposition of pefloxacin, Environ. Toxicol. Pharmacol., 22 (2006) 167-171.

[23] M.A. Ramirez-Vargas, Effects of exposure to malathion on blood glucose concentration: a meta-analysis, Environ. Sci. Pollut. Res. Int., 25 (2018) 3233-3242.

[24] S. Shrestha, Effect of sub-toxic exposure to Malathion on glucose uptake and insulin signaling in L6 myoblast derived myotubes, Drug Chem. Toxicol., 43 (2018) 1-8.

[25] J.D. Wilson, Toxicological profile for malathion. Agency for Toxic Substances and Disease Registry, 2003.

[26] G.L. Ellman, A new and rapid colorimetric determination of acetylcholinesterase activity, Biochem. Pharmacol., 7 (1961) 88-95.

[27] B.L. Furman, Streptozotocin-induced diabetic models in mice and rats, Curr. Protoc. Pharmacol., 70 (2015) 5.47.1-5.47.20.

[28] J.N. Matthews, Analysis of serial measurements in medical research, British Med. J., 300 (1990) 230-235.
[29] I.F. Benzie, J.J. Strain, The ferric reducing ability of plasma (FRAP) as a measure of "antioxidant power": the FRAP assay, Anal. Biochem., 239 (1996) 70-76.

[30] M.-L. Hu, Measurement of protein thiol groups and glutathione in plasma, Methods enzymol., 233 (1993) 380-385.

[31] C.C. Winterbourn, The estimation of red cell superoxide dismutase activity, J. Lab. Clin. Med., 85 (1975) 337-341.

[32] G. Cohen, D. Dembiec, J. Marcus, Measurement of catalase activity in tissue extracts, Anal. Biochem., 34 (1970) 30-38.

[33] D. Lapenna, Reaction conditions affecting the relationship between thiobarbituric acid reactivity and lipid peroxides in human plasma, Free Radic. Biol. Med., 31 (2001) 331-335.

[34] R.L. Levine, Carbonyl assays for determination of oxidatively modified proteins, Methods Enzymol., 233 (1994) 346-357.

[35] J.B. Hammond, N.J. Kruger, The bradford method for protein quantitation, Methods Mol. Biol., 3 (1988) 25-32.

[36] P.K. Gupta, Malathion induced biochemical changes in rat, Acta Pharmacol. Toxicol., 35 (1974) 191-194.

[37] B.O. Laley, M.A. Gibson, Association of hypoglycemia and pancreatic islet tissue with micromelia in malathion-treated chick embryos, Can. J. Zool., 55 (1977) 261-264.

[38] A.L. Arsenault, M.A. Gibson, M.E. Mader, Hypoglycemia in malathion-treated chick embryos, Can. J. Zool., 53 (1975) 1055-1057.

[39] M.A. Rodrigues, Short-term effect of malathion on rats' blood glucose and on glucose utilization by mammalian cells in vitro, Ecotoxicol. Environ. Saf., 12 (1986) 110-113.

[40] M. Trombetta, Review article: type 2 diabetes and chronic liver disease in the Verona diabetes study, Aliment. Pharmacol. Ther. (22 Suppl.) 2 (2005) 24-27.

[41] D. Jira, Toxicity hazard of organophosphate insecticide malathion identified by in vitro 
methods, Neuro. Endocrinol. Lett., (33 Suppl.)

3 (2012) 53-59.

[42] I. El-Bini Dhouib, A comparative study on toxicity induced by carbosulfan and malathion in Wistar rat liver and spleen, Pestic. Biochem. Physiol., 124 (2015) 21-28.

[43] K. Begum, P.S. Rajini, Augmentation of hepatic and renal oxidative stress and disrupted glucose homeostasis by monocrotophos in streptozotocin-induced diabetic rats, Chem. Biol. Interact., 193 (2011) 240-245.

[44] Vismaya, P.S. Rajini, Exacerbation of intestinal brush border enzyme activities and oxidative stress in streptozotocin-induced diabetic rats by monocrotophos, Chem. Biol. Interact., 211 (2014) 11-19.

[45] S. Selmi, S. El-Fazaa, N. Gharbi, Oxidative stress and cholinesterase inhibition in plasma, erythrocyte and brain of rats' pups following lactational exposure to malathion, Environ. Toxicol. Pharmacol., 34 (2012) 753-760.

[46] M.B.S. de, Oxidative stress as an underlying contributor in the development of chronic complications in diabetes mellitus, Int. J. Mol. Sci., 14 (2013) 3265-3284.

[47] R.D. Handy, Chronic diazinon exposure: pathologies of spleen, thymus, blood cells, and lymph nodes are modulated by dietary protein or lipid in the mouse, Toxicol.. 172 (2002) 13-34.

[48] F.P. Possamai, Oxidative stress after acute and sub-chronic malathion intoxication in Wistar rats, Environ. Toxicol. Pharmacol., 23 (2007) 198-204.

[49] M. Akhgari, Biochemical evidence for free radical-induced lipid peroxidation as a mechanism for subchronic toxicity of malathion in blood and liver of rats, Hum. Exp. Toxicol., 22 (2003) 205-211. 